\title{
A new approach to determine geochemical fingerprint of contaminants in stream sediments of Southern Italy
}

\author{
SALVATORE DOMINECH ${ }^{1}$, SHOUYE YANG ${ }^{1}$, MR. \\ POORIA EBRAHIMI ${ }^{2}$, ANTONIO ARUTA ${ }^{2}$, ANNALISE \\ GUARINO $^{2}$, ANDREA GRAMAZIO ${ }^{2}$ AND STEFANO \\ ALBANESE $^{2}$
}

${ }^{1}$ Tongji University

${ }^{2}$ University of Naples Federico II

Presenting Author: dominech@tongji.edu.cn

A geochemical survey was carried out on stream sediments of the Sabato river (with a catchment area of catchment of $\sim 400$ $\mathrm{km}^{2}$ ) which flows in the inner territory of Southern Italy across hilly areas, mostly covered by woods, and valley sectors where both industrial and urban settlements are located. The concentrations of major and trace elements (53 in total) were determined on collected samples through ICP-MS analysis, after an Aqua Regia digestion.

Prior to any elaboration, data were log-ratio transformed, according to Compositional Data Analysis principles, to remove spurious correlations among elements and to better investigate the existence of elemental associations through a robust multivariate statistical analysis. Preliminary, a correlation matrix of log-ratio transformed data was generated to be used as a discriminatory tool to significantly reduce the dimension of the investigated dataset and to split the original dataset into subsets.

In facts, two distinct subsets of variables were identified. A first subset includes variables with a highest count of strong correlations (>.80) (HCEs), a second subset includes elements with the highest count of moderate correlations (MCEs) $(<.80$ and $>.60)$, eventually highlighting associations related with secondary geogenic or anthropogenic processes. Subsequently, two Principal Factor Analyses (PFA) were performed separately on both datasets.

The PFA on HCEs generated a two-factor model:

1) $\mathrm{Be}, \mathrm{Ce}, \mathrm{Al}, \mathrm{As}, \mathrm{La}, \mathrm{Cs}$ and $\mathrm{Tl}$ showing spatial correspondence of highest scores with pyroclastic covers;

2) $\mathrm{Na}, \mathrm{K},-(\mathrm{Ni}, \mathrm{Cr})$ to be assumed as a proxy to assess the prevalence of the coarser fraction over the finer one in the grainsize.

The PFA on MCEs also generated a two-factor model:

1) $\mathrm{Zn}, \mathrm{Pb}, \mathrm{Cu}, \mathrm{P}$ probably showing the presence of long-term agricultural practice within the catchment;

2) $\mathrm{Mg}, \mathrm{Ca}$ to be associated with the weathering of locally outcropping carbonates.

A further transformation of the data to isometric log-ratio (ilr) coordinates based on the PFA results allowed to better discriminate sources and elemental patterns. 